\title{
Majoritarian vs. Minoritarian Defaults
}

\author{
Ian Ayres* and Robert Gertner**
}

Recent theoretical analysis of contract default rules has devoted significant attention to the use of penalty default rules as a way to induce a contractor to reveal private information. Penalty default rules demonstrate how efficient rules cannot be derived by simply asking what most parties would have contracted for had they written a complete contract. Such "majoritarian" default rules derive from an implicit assumption about the reason why a particular contract is incomplete. A fuller efficiency analysis tries to understand the reasons why contracts are incomplete and how different default rules affect the efficiency of the contracting process and the contracts themselves. Our goal here is to show how an understanding of the underlying causes of contractual incompleteness informs the optimal choice of default rules.

Barry Adler's fine articlel correctly identifies a new reason why it may be difficult to use "penalty" or "information-forcing" defaults to induce contractors to reveal private information about their personal attributes (what game-theorists tend to call their "type"). In an earlier article, ${ }^{2}$ we had shown that, when one side to a contract has private information and the other side has market power, the privately informed party may be reluctant to contract around a penalty default (and thereby reveal information) if doing so would allow the other side to extract more of the gains from trade. ${ }^{3}$ But Adler has shown that even when the private information and the market power are on the same side of the contract-as when a privately informed buyer contracts in a market with competitive sellers-the privately informed party may still be reluctant to contract around a penalty default. ${ }^{4}$ In our earlier model, the

* William K. Townsend Professor of Law, Yale Law School.

** Professor of Economics and Strategy, Graduate School of Business, University of Chicago.

1. See Barry E. Adler, The Questionable Ascent of Hadley v. Baxendale, 51 STAN. L. REV. 1547 (1999).

2. See Ian Ayres \& Robert Gertner, Strategic Contractual Inefficiency and the Optimal Choice of Legal Rules, 101 YALE L.J. 729 (1992).

3. In particular, we showed in a stylized version of Hadley that buyers who would experience uncharacteristically high potential damages from a seller might be reluctant to reveal this information if sellers had market power and might use the information about the buyer's value to charge a supracompetitive price. See id. at 738-41. Our model was an attempt to formalize some of the insights of Jason Scott Johnston, Strategic Bargaining and the Economic Theory of Contract Default Rules, 100 YALE L.J. 615 (1990).

4. See generally Adler, supra note 1. 
informed buyer was reluctant to contract around the penalty defaults because doing so would subject her to a supracompetitive price; in Adler's model, the informed party is reluctant to contract around penalty defaults because doing so would destroy the subsidized pricing that the privately informed party receives by hiding out in the undifferentiated pool.

Adler should be credited for identifying this additional reason why privately informed parties may be reluctant to contract around default rules. But showing that it may be harder to induce information revelation with a particular type of penalty default is not an argument in favor of setting "hypothetical" or "majoritarian" defaults. Efficiency gap filling should grow out of one's substantive theory of why particular contracts are incomplete. Adler's insight actually strengthens an implication of our earlier articles: The effect of a particular default rule on information revelation, and thus on efficiency, depends on numerous characteristics of the contracting environment that are independent of the "hypothetical contracting" inquiry-that is, merely assessing what the parties would have contracted for if there were no private information. Other factors, including the distribution of types, the magnitude of transaction costs, and the distribution of bargaining power, will all affect the likelihood that a particular penalty default will induce separation and enhance efficiency. Adler adds another factor to this list-the possibility that revealing information might eliminate an informed party's subsidy from pooling. Even these results underestimate the problem of predicting outcomes since they were derived in overly simplistic and unrealistic models of contract negotiations whose purpose was merely to show the possibility that penalty defaults could be efficient.

Majoritarian theories of default choice are implicitly derived from a transaction cost based theory of incomplete contracts. But when contracts are strategically incomplete because of one side's private information, then there is no reason to think that majoritarian or hypothetical default setting will conduce to efficiency. When transaction costs are low and contracts are incomplete because of private information, the potential welfare losses from choosing an inefficient default are largely independent of transaction costs and, as we have previously shown, can dwarf the mere out-of-pocket costs of contracting around. ${ }^{5}$

The normative implication of Adler's analysis is not that policymakers should reflexively retreat to majoritarian defaults, but instead the message is that "life is hard." When contracts are incomplete because of a contractor's private information about her "type," it will be difficult for efficiencyminded lawmakers to identify the efficient default. ${ }^{6}$ Penalty defaults at times

5. See Ayres \& Gertner, supra note 2, at 762.

6. As we argued earlier,

relatively simple contractual settings can give rise to enormous complexity. While we can show that different default nules-and in certain circumstances, immutable rules-would be 
will still be efficient, ${ }^{7}$ but Adler shows there is a narrower range of circumstances where information-forcing rules will produce efficient separation making it difficult for lawmakers to determine when they will be effective.

Adler's analysis, however, is only about one type of minoritarian rule-a penalty default set to cause information about contractor's type. ${ }^{8}$ In this comment, we develop a simple model that identifies four other rationales for minoritarian rules based on

(1) different private costs of contracting around,

(2) different private costs of failing to contract around,

(3) different public costs of filling gaps, and

(4) ignorance of the law.

The choice of an efficient default does not boil down merely to a choice between the majoritarian rule (for which most contractors would have contracted) and a penalty default designed to induce a contractor to reveal information about her type. Instead, efficiency-minded lawmakers will often need to consider the other four factors to decide whether it is more efficient to choose a default that only a minority values.

In our original article, ${ }^{9}$ we intended to use the possibility of penalty defaults as a particularly vivid example of why the efficiency-maximizing law might at times diverge from majoritarian gapfilling. We were not the first to see that certain defaults- the Hadley default in particular-could induce contracting that revealed information, ${ }^{10}$ but we were the first to see that penalty defaults were inconsistent with the then dominant theory of choosing gapfillers that minimized the need of private parties to contract around. ${ }^{11}$

theoretically efficient, our model suggests that there is small hope that lawmakers will be able to divine the efficient rule in practice. Id. at 733.

7. Adler admits this as well. See Adler, supra note 1, at 1582 (noting that penalty defaults still "could be efficient").

8. See id. at 1549.

9. See Ian Ayres \& Robert Gertner, Filling Gaps in Incomplete Contracts: An Economic Theory of Default Rules, 99 YALE L.J. 87 (1989).

10. See Charles J. Goetz \& Robert E. Scott, Enforcing Promises: An Examination of the Basis of Contract, 89 YALE L.J. 1261, 1299-1300 (1980); see also RICHARD A. POSNER, ECONOMIC ANALYSIS OF LAW 114 (3d ed. 1988); William Bishop, The Contract-Tort Boundary and the Economics of Insurance, $12 \mathrm{~J}$. LEGAL STUD. 241, 253 (1983).

11. Lucian Bebchuk and Steven Shavell had independently written an unpublished manuscript with a similar model of Hadley that came to our attention literally on the last day of editing the galleys of our original article (even though we had previously delivered our article at Chicago, Georgetown, Michigan, Northwestern, and Illinois law schools). Lucian Arye Bebchuk \& Steven Shavell, Information and the Scope of Liability for Breach of Contract: The Rule of Hadley v. Baxendale, 7 J.L. ECON. \& ORG. 284 (1991). While their mathematical model is similar, their manuscript at that time did not relate Hadley to the then accepted ("majoritarian" or "hypothetical") theories of default choice. Their article did, however, go further than our article in identifying the particular parameter values for which the limited-liability default would be efficient. Our article only emphasized the possibility that the Hadley default might be efficient for certain parameter values. See, e.g., Ayres \& Gertner, supra note 9, at 112 ("If inequality (9) holds ..., then the costs of 
Information-forcing defaults try to induce explicit contracting that might have been avoided with the use of alternative defaults. But there are other rationales besides "information forcing" that might justify setting nonmajoritarian gapfillers.

\section{RATIONALES FOR MINORITARIAN RULES}

In an earlier article, we sketched a simple model of default choice. ${ }^{12}$ In this section, we extend the model to show not only when majoritarian rules will be efficient, but also to show a variety of reasons why minoritarian rules might be superior. ${ }^{13}$ Imagine that a policymaker is choosing between two different defaults: "one" and "two." Imagine that for $i$ equal to 1 or 2:

$\alpha_{i}=$ the percentage of the population of contracting parties that, in a world without private information, would prefer to use default $i$;

$\beta_{i}=$ the percentage of type $i$ contracting parties who, in equilibrium, would expressly contract for rule $i$ if the other rule were the default;

$c_{i}=$ the private costs of expressly "contracting" for rule $i$;

$f_{i}=$ the inefficiency generated if a type $i$ contracting party "fails" to expressly contract for rule $i$ when the other rule is the default; ${ }^{14}$

$e_{i}=$ the expected "externalized" public cost of filling the gap for a type $i$ con-

tracting party who fails to expressly contract around default rule $i .^{15}$

pooling exceed the costs of separating, and the Hadley default is efficient even though it is not what the high-damage millers would have wanted."). In order to overthrow the academic consensus that defaults should mimic what the parties would have contracted for, it was sufficient for our purposes to show that a "penalty" default might be efficient for some plausible parameter values.

12. See Ayres \& Gertner, supra note 9, at 113-15.

13. If it were costless to negotiate and draft contractual provisions describing the contracting obligations for every conceivable future contingency (that is what game-theorists would call every possible "state of the world"), then we would not expect to see obligational gaps in contracts. Contracting costs are the primary if not sole reason for obligation incompleteness. Private information might still cause these obligationally complete contracts to be insufficiently state contingent, because one privately informed contractor might be reluctant to reveal material information to the other side, but private information by itself would not provide a reason why the parties would not fill obligational gaps. Indeed, the possibility that one party might be mistaken about the law in a world with costless contracting would induce the parties to contract to duplicate the default obligations that would obtain in the absence of the explicit provisions.

14. As suggested in the standard Hadley model, some of the inefficiency of pooling equilibria may stem from inefficient precaution taken with respect to those parties who nonstrategically remain in the pool. However, as Adler has nicely emphasized, the size of this inefficiency will often be a function of the percentage of high-cost types that choose to hide strategically in the low-cost pool. Thus, even though expression (1), see text accompanying notes 15-16 infra, measures the costs of failing to contract as being tied to the percentage of disfavored contracting types who fail to contract around $\left(\alpha_{2}-\beta_{2}\right)$, some of the inefficiency of disfavored types failing to contract around may be visited on the favored contracting types $\left(\alpha_{1}\right)$ who fail to expressly contract.

15. As will be discussed at text accompanying notes 18-20 infra, courts may expend more resources determining how to implement certain types of defaults than others. The expected size of this external gapfilling cost $\left(e_{i}\right)$ will turn on, among other things, how frequently the court will be called upon to fill the gap as well as on the substance of the particular default. For example, setting 
These five variables can be used to assess the private and public cost of particular defaults. For example, the costs associated with default one will be:

$$
c_{2} \beta_{2}+f_{2}\left(\alpha_{2}-\beta_{2}\right)+e_{1}\left(1-\beta_{2}\right)
$$

A corresponding expression exists for the costs associated with default two. ${ }^{16}$ This expression captures the private costs of contracting $\left(c_{2} \beta_{2}\right)$, the private costs of failing to contract $\left(f_{2}\left(\alpha_{2}-\beta_{2}\right)\right)$, and the public costs of filling gaps $\left(e_{1}\left(1-\beta_{2}\right)\right)$. One could imagine more complicated models where there were also public costs of interpreting express contracts, or where some type $i$ contractors would expressly contract for $i$ even when the default rule was $i$, but these assumptions are sufficient to generate a wide variety of minoritarian rationales. ${ }^{17}$ In this simpler model, efficiency-minded lawmakers would choose the default that produced the lowest expected social costs. Comparing the expression in (1) to the corresponding expression for the costs of default two, it is possible to deduce that default one will only be efficient if:

$$
\alpha_{1}>\frac{f_{2}+e_{1}\left(1-\beta_{2}\right)-e_{2}\left(1-\beta_{1}\right)+\beta_{2}\left(c_{2}-f_{2}\right)-\beta_{1}\left(c_{1}-f_{1}\right)}{f_{1}+f_{2}} .
$$

The complexity of the right-hand side sharply distinguishes this model from naive majoritarianism which would suggest that rule one is the efficient default if $\alpha_{1}>.5$. However, in a world without private information, even this relatively complex model will often simplify to something much closer to a majoritarian analysis. Without private information, this model predicts extreme equilibria where either all or none of the disfavored type would contract around the governing default. For example, if rule one were the default, type two contractors would all contract expressly for rule two when $c_{2}<f_{2}$ so that in equilibrium $\beta_{2}=\alpha_{2}$. Or in the alternative, when $c_{2}>f_{2}$, the model would predict that none of the type two contractors would contract around so that $\beta_{2}=0$. Majoritarianism can fare well at either extreme. When $\beta_{i}=\alpha_{i}$, then simplifying the inequality (2), we can see that default one is efficient if:

the default quantity of a contract to zero would require relatively few resources, while filling a contractual gap with the "reasonable" quantity that the parties would have contracted for would undoubtedly be more costly.

16. The model can also be generalized to accommodate the choice among multiple potential defaults. See Ayers \& Gertner, supra note 12, at 116 n.124.

17. In more complicated models, parties might also mistakenly contract away from their preferred rule. 


$$
\alpha_{1}<\frac{\left(c_{2}-e_{2}\right)}{\left(c_{1}-e_{1}\right)+\left(c_{2}-e_{2}\right)} .
$$

As long as the private costs of contracting around and the external public costs of filling gaps are approximately the same, this inequality simplifies to the majoritarian default-setting criterion. Conversely, in a world without private information where costs of contracting preclude anyone from contracting around a default so that $\beta_{i}=0$, then inequality (2) simplifies to:

$$
\alpha_{1}>\frac{\left(f_{2}+e_{1}-e_{2}\right)}{\left(f_{1}+f_{2}\right)}
$$

If the external public costs of filling gaps and the costs of failing to contract around a disfavored default are approximately the same, inequality (4) also reduces to the majoritarian criterion (i.e., choose default one if $\alpha_{1}>.5$ ).

Yet, even in a world without private information, the foregoing inequalities provide a number of reasons why efficiency-minded lawmakers might prefer a default that only a minority of the parties prefer.

\section{A. Different Public Costs of Gapfilling}

Even though most models of gapfilling have not focused on the public costs of filling gaps, default provisions that are standards will often be more expensive to implement than default provisions that are rules. ${ }^{18}$ Courts, for example, in filling a price gap currently need to expend judicial resources to determine what the "reasonable" price would have been. Particularly in a world where parties do not bear the full social cost of public litigation, courts may want to choose a default that avoids expensive public gapfilling costs. The long tradition of refúsing to enforce contracts that are excessively vague is consistent with this norm. ${ }^{19}$ Courts avoid the effort of filling speculative gaps, and instead supply a low cost default of nonenforcement. Instead of filling the quantity gap with the reasonable quantity, which is relatively costly to calculate, courts choose a zero-quantity default that is relatively

18. See Ian Ayres, Preliminary Thoughts on Optimal Tailoring of Contractual Rules, 3 S. CAL. INTERDISC. L.J. 1 (1993); Louis Kaplow, Rules Versus Standards: An Economic Analysis, 42 DUKE L.J. 557 (1992).

19. See U.C.C. $\$ 2-204(3)$ (1977) (establishing that a contract fails for indefiniteness if there is not "a reasonably certain basis for giving an appropriate remedy"). 
cheap to implement in terms of court expenditures. ${ }^{20}$ Particularly where the costs of contracting around a default are lower than the expected costs of ex post judicial gapfilling $\left(c_{1}<e_{1}\right)$, courts may decide that it is preferable to set a default that only a minority of parties prefer.

For example, imagine the following stylized choice between two quantity defaults (for written contracts that fail to specify a quantity) where a lawmaker is to choose between setting a "reasonable" quantity default and a zero-quantity default. To commensurate this example with the foregoing model, imagine that the cost of contracting for an express quantity is one, but the costs of having the court calculate a reasonable quantity ex post is five (while the court can costlessly implement a zero-quantity default). Assume that none of the contracting parties substantively prefer trading a zeroquantity (after all, why go to the trouble of negotiating a contract for a zeroquantity). And in the shadow of a "reasonable" quantity default, assume that eighty percent of the contracting parties contract for an explicit quantity, ${ }^{21}$ while in the shadow of a zero-quantity default assume that all contractors will expressly state the quantity desired. These assumptions suggest that the costs of a reasonable quantity default will be eighty percent greater than the cost of a zero-quantity default. ${ }^{22}$ The zero-quantity default represents an extreme minoritarian rule. Even though none of the parties drafting written contracts want a quantity of zero, the zero-quantity default can promote efficiency because it reduces the expected external costs of gapfilling. The model suggests that ceteris paribus, efficiency-minded lawmakers should tend to favor defaults that impose lower costs of public gapfilling. Moreover, the model provides some guidance on when efficiency-minded lawmakers will choose to fill gaps with what the parties would have bargained for, and when they will refuse to expend the resources to determine what a "reasonable" provision would be and instead conclude that the contract is unenforceably void for vagueness. When the expected cost of judicially calculating the reasonable term is great compared to the costs of private gapfilling,

20. The most current proposed revision to UCC article 2 changes this default by replacing courts to fill quantities gaps with reasonable amounts. See U.C.C. $\$ 2-201$ (a) (Revised Draft Feb. 1, 1999) ("A record is not incomplete merely because it omits a term including a quantity term.").

21. In a more reductive model, none of the parties would contract for an explicit quantity because they could avoid the transaction costs of express contracting and free-ride on the courts' ex post quantity determination. However, if courts only imperfectly fill the gap with the quantity that the parties would have wanted, one can easily imagine contractors finding it in their interest to contract around "reasonable" gap fillers. We see just this phenomena with regard to price, where the default rule is the reasonable price. In this example, all that is necessary is that more people expressly contract for a quantity in the shadow of a zero-quantity default than a reasonable quantity default.

22. Under a zero-quantity default, $100 \%$ of the contractors will incur a contracting cost of one. Under a reasonable quantity default, $80 \%$ of the contractors will incur a contracting cost of one and $20 \%$ of the contractors will fail to contract, creating a public implementation costs of five-causing an expected cost per contract of $1.8(.8(1)+.2(5)=1.8$, which is $80 \%$ greater than $1(1)=1)$. 
courts will be more likely to void the contract for vagueness; when the expected cost of judicially calculating the reasonable term is relatively small compared to the costs of private gapfilling, courts will be more likely to provide the "reasonable" term. As we have previously written with regard to the different legal treatment of price and quantity defaults,

[i]t is not systematically easier for parties to figure out the quantity than the price ex ante, but it is systematically harder for courts to figure out the quantity than the price ex post. To estimate a reasonable price, courts can largely rely on market information of the type "How much were rutabagas selling for on July 3?" But to estimate a reasonable quantity, courts would need to undertake a more costly analysis of the individual litigants of the type "How much did the buyer and the seller value the marginal rutabagas?"23

The relatively high judicial cost of calculating how the parties would have filled certain obligational gaps can justify the common law impulse to void certain contracts for vagueness - even though the parties did not intend for them to be voided. Differences in the costs of public gapfilling (differences in $e_{i}$ ) can therefore justify the use of minoritarian defaults.

\section{B. Different External Effects}

The costs of public gapfilling (the $e_{i}$ ) are negative externalities of failing to contract. To the extent that contractors do not pay the full cost of public litigation, they will not take these costs into account in deciding whether to contract around a gapfilling rule. But failing to contract around certain defaults may create other types of externalities as well that might be either positive (i.e., welfare enhancing) or negative (welfare decreasing). The $e_{i}$ variable of the foregoing model can be more generally interpreted as the externality effect of failing to contract around the default $i_{.}{ }^{24}$

Externalities are important because the costs of express contracting often make defaults "sticky." More parties will be covered by a rule if we make that rule a default than will be covered by that rule if we make a different rule the default. No one has ever suggested that, in equilibrium, more people would affirmatively opt for a given rule (" $X$ ") if some other rule was the default than would be covered by rule $X$ by remaining silent if $\alpha$ was the default. The number of people who fail to contract around a given default is always greater than the number of people who would affirmatively contract for the substantive provision in the shadow of some other rule. ${ }^{25}$ This is the iron law of default inertia. A normative implication of inertia is that efficiency-minded lawmakers should tend to prefer defaults that produce posi-

23. Ayers \& Gertner, supra note 12, at 96.

24. When the external effect is welfare enhancing, $e_{i}$ will be negative; when the external effect is welfare reducing, $e_{i}$ will be a positive cost (as was the case with the judicial costs of gapfilling).

25. In terms of our model, this inertia effect implies that $\beta_{1}$ will never be greater than $\alpha_{1}$. 
tive externalities because, by making such rules the default, we will increase the number of contractors in equilibrium who are covered by the desired rule.

Ceteris paribus, the model suggests the unsurprising result that defaults that produce positive externalities should be favored while defaults that produce negative externalities should be disfavored. This normative implication is consistent with at least one strand of our common law tradition which employs a similar default canon of construction for resolving contractual ambiguities. ${ }^{26}$ For example, section 207 of the Restatement (Second) of Contracts ordains that "[i]n choosing among the reasonable meanings of a promise ... a meaning that serves the public interest is generally preferred."27 And a similar public-regarding canon of construction has been proposed and fitfully applied with regard to statutory interpretation..$^{28}$

Failing to contract around a rule might create positive or negative externalities for other contractors who fail to contract around. In models with private information, failing to contract around can create a "pooling equilibrium" in which, for example, the failure of bad types to contract around produces a negative externality on good types who fail to contract around. Failing to contract around a default can also produce a positive externality by giving rise to a richer set of precedent and trade usage under the default.

Failing to contract around may also create externalities for third parties who are not engaging in similar types of contracting. For example, Richard Epstein has argued that there should not be an immutable rule against race discrimination in employment. ${ }^{29}$ Even if we accepted Epstein's thesis (which we do not), we would prefer an opt-out default regime (in which there was Title VII liability for employment discrimination unless expressly disclaimed) to an opt-in default regime, because there is a positive externality to reducing the spheres of life in which racial discrimination is tolerated. Because of inertia, it is clear that fewer employers would have the freedom to discriminate in an opt-out regime than in an opt-in regime.

While the presence of positive or negative externalities at times militates toward mandatory (or immutable) rules which restrict the parties' abilities to contract around, there will be circumstances in which blanket prohibitions create sufficiently deleterious reactions by private contractors. Sometimes, the best we can hope for is to channel some percentage of contractors away from a disfavored practice. Favoring defaults which promote positive exter-

26. Chamy has shown that rules of contractual interpretation are fundamentally defaults. See David Chany, Hypothetical Bargains: The Normative Structure of Contract Interpretation, 89 MICH. L. REV. 1815 (1991).

27. RESTATEMENT (SECOND) OF CONTRACTS $\$ 207$ (1979).

28. See, e.g., Jonathan R. Macey, Promoting Public-Regarding Legislation Through Statutory Interpretation: An Interest Group Model, 86 COLUM. L. REV. 223 (1986).

29. See Richard A. Epstein, Forbidden Grounds: The Case Against EMployment DISCRIMINATION LAWS 17 (1992). 
nalities (or which avoid negative externalities) is an important way for policymakers to accommodate this intermediate mission.

\section{Different Private Costs of Gapfilling}

The foregoing model also teaches that differences in the private costs of express contracting-i.e., differences in $c_{-}$-can justify the use of minoritarian defaults. Ceteris paribus, the model suggests favoring defaults with higher costs of express contracting. Even if the only costs of default choice were the costs of express contracting, efficiency-minded lawmakers should not try to minimize the number of contractors who are induced to contract, but rather the total costs of express contracting (which will equal the number of parties who expressly contract multiplied by the per contract costs of express contracting). A majoritarian default may not be efficient if the costs of contracting around the majoritarian rule are systematically higher than the costs of contracting around a minoritarian default. In terms of the foregoing inequality (3), even when a majority of contractors favor default one $\left(\alpha_{1}>.5\right)$, default two may be efficient if the costs of contracting expressly for rule two are higher than the cost of contracting for rule one $\left(c_{2}>c_{1}\right) \cdot{ }^{30}$

Appreciating differences in the costs of contracting might justify the current muddy defaults concerning managers' duty of care to their corporation instead of the relatively crystalline default of no potential managerial liability (an alternative which can be affirmatively contracted for in Delaware). ${ }^{31}$ Even if a majority of corporations prefer abolishing the managerial duty of care-and a majority of large corporations affirmatively contract for such treatment in Delaware ${ }^{32}$ - it might be efficient to maintain the current muddy default of potential liability because of differences in contracting costs. As one of us has argued,

[i]n simple terms, it may be cheaper for corporations to contract for crystals than mud. If the default rule involves courts in muddy ex post balancing of the activity's costs and benefits, corporations that prefer unconditional rules (that unconditionally either allow or prohibit particular management behavior) can cheaply contract for them. In contrast, if the default rule unconditionally allows or unconditionally prohibits that behavior, it will be much more difficult for the parties to contract for a muddy rule which asks courts to make contractual obligations fully contingent on future states of the world.

Corporations desirous of muddy ex post determinations could cheaply insert ex ante muddy provision that allow managers to engage in an activity when it is "reasonable" or ... when it is "in shareholders' interest." However, forcing even a minority of corporations to opt for this kind of language is likely to

30. David Charny has independently noted this point. See Charny, supra note 26, at 1849.

31. See DEL. CoDE ANN. tit. 8, § 102(b)(7) (1991 \& Supp. 1998).

32. See Michael Bradley \& Cindy A. Schipani, The Relevance of the Duty of Care Standard in Corporate Governance, 75 IOWA L. REV. 1, 62 (1985). 
be less efficient than starting with a muddy (ex post conditioning) default and forcing a majority of corporations to contract for an unconditional provision. Because the ex ante formulations of reasonableness by individual corporations can take so many different forms, there is a much smaller likelihood of developing a coherent (and therefore valuable) precedential base..$^{33}$

Ceteris paribus, efficiency-minded lawmakers might tend to favor standards over rules because parties may have higher costs contracting for effective state-contingent standards. ${ }^{34}$

A similar analysis might suggest that our current reorganization/bankruptcy regime might be a more efficient default than a simpler, more rule-like default such as liquidation and absolute priority. It is easy to devise a regime for parties to contract for absolute priority or liquidation upon default, ${ }^{35}$ but not so easy to contract for the current reorganization rules or the standard-like deviations from absolute priority. Even if a majority of debt contracts prefer absolute priority and/or liquidation treatment, ${ }^{36}$ setting an alternative default might economize on transaction costs.

It is important to stress that there will often be a trade-off between favoring defaults that avoid high costs of express contracting and favoring rules that avoid high costs of public gapfilling. Previously, we criticized using "reasonableness" standards as defaults because they might impose excessively high costs of public gapfilling, ${ }^{37}$ but as argued here, standards often have the advantage of imposing lower costs of private contracting. What

33. Ian Ayres, Making a Difference: The Contractual Contributions of Easterbrook and Fischel, 59 U. CHI. L. REV. 1391, 1405 (1992); see also Marcel Kahan \& Michael Klausner, Path Dependence in Corporate Contracting: Increasing Returns, Herd Behavior, and Cognitive Biases, 74 WASH. U. L.Q. 347 (1996) (arguing that standardization is a form of path dependence in corporate contracts); Marcel Kahan \& Michael Klausner, Standardization and Innovation in Corporate Contracting (Or, "The Economics of Boilerplate"), 83 VA. L. REV. 713, 738 (1997) (explaining how an underwriter convinces a firm to commit to boilerplate terminology); Mark A. Lemley \& David McGowan, Legal Implications of Network Economic Effects, 86 CAL. L. REV. 479 (1998).

34. See Russell Korobkin, The Status Quo Bias and Contract Default Rules, 83 CoRNELL L. REV. 608 (1998). At a minimum, lawmakers may want to provide a menu of choices that are biased to include standard-like options so that coherent precedents can form around particular options.

35. See Barry E. Adler, Financial and Political Theories of American Corporate Bankruptcy, 45 STAN. L. REV. 311, 314 (1993) (explaining that bankruptcy law replaces creditors' rights to act individually within a collective regime); Bernard S. Black, Is Corporate Law Trivial?: A Political and Economic Analysis, 84 Nw. U. L. REV. 542, 544, 551.62 (1990) (maintaining that mandatory corporate law is trivial because it does not prevent companies from establishing their own rules of govemance).

36. Firms may desire a regime other than absolute priority. For example, if equity receives some value in reorganization, it will have a credible threat to file for bankruptcy that it would not have under an absolute priority regime. This threat may induce creditors to lend additional funds to keep the firm operating which in turn can mitigate problems of underinvestment caused by financial distress and multiple creditors. Although creditors will demand higher initial interest rates to compensate for the deviation from absolute priority, the overall value to the firm may be positive. See Robert Gertner \& David Scharfstein, A Theory of Workouts and the Effects of Reorganization Law, 46 J. FIN. 1189 (1991).

37. See text accompanying notes 18-23 supra. 
should a lawmaker do when confronted with a choice between one default that has low costs of both public implementation and express contracting, and another default which has relatively high costs of both public implementation and express contracting? Inequality (3) shows how these two effects should be traded off when all contracting types will contract around disfavored defaults for their preferred rule (i.e., under the assumption that $\beta_{i}=\alpha_{i}$ ). Minoritarian standards-which impose high public gapfilling costs - can still be efficient defaults. It is important to note that the costs of public gapfilling are only incurred when there is a dispute. If disputes are relatively unlikely, so that parties are likely to agree on a "reasonable" price, then public gapfilling may provide a benefit for parties attempting to negotiate the ex post reasonable price. ${ }^{38}$

\section{Different Propensity to Contract Around}

As noted above, contractual models without private information tend to produce knife-edged results in which either all of the disfavored contractual types contract around a default or none do. Contractual equilibria in which all of the disfavored types expressly contract $\left(\beta_{i}=\alpha_{i}\right)$ are fully "separating" because different contracting types enter into separate types of contracting. Contractual equilibria in which none of the disfavored types contract around $\left(\beta_{i}=0\right)$ are fully pooling, because the different contracting types pool on the undifferentiated default provision.

But, in richer models, partial pooling (also referred to as partial separation) equilibria are also possible. In our model, partial pooling is designated by equilibria in which $\alpha_{i}>\beta_{i}>0$. Private information in particular can create different propensities to pool or separate. ${ }^{39}$ Using our nomenclature, type two contractors would have a high propensity to contract around default one if $\beta_{2}$ rose close to the level of $\alpha_{2}$. In contrast, type two contractors would have a low propensity to contract around default one if $\beta_{2}$ fell closer to 0 .

When different contracting types have different propensities to contract around dispreferred defaults, our model suggests that ceteris paribus law-

38. For example, assume that the cost of contracting expressly for the business judgement rule (bjr) standard of care is 10 while the cost of contracting for an absolute liability waiver (lw) of any duty of care is 1 . And assume that the respective public costs of filling the gap for the business judgement standard and the waiver default in any ensuing litigation are 50 and 5 respectively. Finally, assume that the probability of ensuing litigation is $5 \%$ under the bjr default, but only $1 \%$ in contracts that have waived potential liability. The expected public costs of gapfilling under the two regimes will be the product of the litigation costs times the probability of litigation, which in this example yields $e_{\mathrm{bjr}}=2.5$ and $e_{\mathrm{lw}}=.05$. Applying these assumed values to inequality (3) suggests that the relatively vague standard of care will be the more efficient default even if as few as $12 \%$ of the contractors prefer the standard to the rule.

39. Intermediate propensities to pool could be caused in models without private information if, for example, contractors of a particular type faced different costs of expressly contracting. 
makers should tend to favor as defaults the preferred rules of contractors who have a relatively low propensity to contract around other defaults. In the nomenclature of our model, this means favoring defaults with low $\beta$ s. When failing to contract around a default creates greater public and private costs than express contracting (e.g., $f_{i}+e_{i}>c_{i}$ ), then choosing defaults with low $\beta \mathrm{s}$ tends to limit the number of parties who fail to contract. By definition, the other contracting types that disprefer the chosen default will have a higher propensity to contract around it and produce a more separating equilibrium.

Contractors' private information about the law provides an important reason why different contracting types may have different propensities to contract around different defaults. Knowledge about the employment-at-will default provides a useful example. Pauline Kim has recently published evidence indicating that employees may be systematically misinformed about the extent of their rights if they and their employers fail to opt out of the employment-at-will default. ${ }^{40}$ In particular, Kim shows that, when the employment contract is silent, employees are likely to mistakenly believe that employers may only fire them for just cause. ${ }^{41}$ It is much more likely that employers, as repeat players, will be correctly informed about the "sound of silence"-that is, the default meaning of silence. ${ }^{42}$ When one party to the contract has a systematic misbelief that a default is more favorable to them than it is in fact, we are likely to see a low propensity to contract around the default.

Because employees apparently are systematically optimistic (in believing that silence entitles them to just-cause protection compared to the superior knowledge of employers), we can expect that an employment-at-will contract will produce a lower propensity to contract around. Even though some proportion of contractors may be jointly better off with just-cause coverage, these just-cause types may fail to contract around the employment-at-will default. The employees mistakenly believe that they are contracting for justcause protection, and the employers who know otherwise will be reluctant to raise the issue (and thereby reduce the employer's legal rights). ${ }^{43}$ In contrast, we should expect a relatively high propensity of employment-at-will types to contract around a just-cause default. The employers, as repeat players, will know that just-cause treatment will result if the contract is silent and will affirmatively move to contract around what, by assumption, is an inefficient term with regard to this subset of employment relationships.

40. See Pauline T. Kim, Bargaining with Imperfect Information: A Study of Worker Perceptions of Legal Protection in an At-Will World, 83 CORNELL L. REV. 105 (1997).

41. See id. at 133-43.

42. See Randy E. Bamett, The Sound of Silence: Default Rules and Contractual Consent, 78 VA. L. REV. 821, 822 (1992).

43. Indeed, in such a regime employees believe that they are contracting for just-cause protection may be willing to make wage concessions. 
Imagine that some employment relationships are more efficient as employment-at-will (possibly because employers' ongoing reputational concerns are a more efficient way to deter firing for bad reasons than submitting this aspect of the relationship to the vagaries of jury review) but that other employment relationships are more efficient if employers can only fire for just cause (possibly because it is a declining industry with fewer prospective reputational concerns). We can again apply the simple algebra of the original model to show that a just-cause default might be efficient even if only a minority of employment relationships are efficiently governed by such a standard. To focus on the propensity to contract around different rules, assume that the costs of expressly contracting $\left(c_{i}\right)$, failing to contract $\left(f_{i}\right)$, and public gapfilling $\left(e_{i}\right)$ do not vary across rules. Specifically, we assume that $c_{1}=c_{2}=1, f_{1}=f_{2}=5$, and $e_{1}=e_{2}=0$. To capture the different propensity of contracting types to contract around dispreferred defaults, we assume that all of the at-will types (aw) will contract around a just-cause default $\left(\beta_{\mathrm{aw}}=\alpha_{\mathrm{aw}}\right)$, but that only fifty percent of the just-cause types (jc) will contract around an employment-at-will default $\left(\beta_{\mathrm{jc}}=.5 \alpha_{\mathrm{jc}}\right)$.

Under these assumptions, it is possible to show that just cause will be the efficient default even if only twenty-six percent of contractors substantively prefer just-cause provisions. And as the propensity of just-cause types to contract around employment-at-will falls, this minoritarian bias increases. For example, if only ten percent of the just-cause contractors succeeded in contracting around an employment-at-will default, then efficiency-minded lawmakers should prefer a just-cause default even if only eighteen percent of employment contractors substantively preferred just-cause provisions. ${ }^{44}$

\section{E. Different Costs of Failing to Contract Around}

Finally, our basic model suggests that when different contracting types experience different levels of inefficiency from failing to contract for their preferred provisions, then efficiency-minded courts will be attuned to the

44. If we define the proportion of just-cause types to contract around an employment-at-will default to be "prop," then the costs of an employment-at-will-default would be:

while the cost of a just-cause default would be:

$$
1 \text { (prop) }\left(\alpha_{j c}\right)+5\left(\alpha_{j c}-(\text { prop})\left(\alpha_{j c}\right)\right)
$$

$$
1\left(\alpha_{a w}\right)+5(0)
$$

Substituting $\alpha_{\mathrm{jc}}=1-\alpha_{\mathrm{aw}}$, it is possible to show that an employment-at-will default will only be efficient if the proportion of contractors who substantively prefer employment-at-will provisions is greater than:

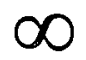

This critical supermajoritarian requirement equals $75 \%$ when prop $=.5$ and $82.1 \%$ when prop $=.1$. Of course, if a sufficiently large proportion of contractors prefer employment at-will coverage, it will be the more efficient default notwithstanding the propensity effect. 
costs of failing to contract in choosing to contract. Such failures to contract will only be relevant in contexts were there is less than complete separation (i.e., where $\beta_{i}<\alpha_{i}$ ) so that in equilibrium there will be some contracting types who fail to contract around dispreferred defaults. In such circumstances, efficiency-minded lawmakers should, ceteris paribus, tend to favor defaults which are preferred by parties who would experience higher costs of failing to contract around dispreferred defaults. This is most likely to occur in situations where private information, rather than transaction costs, is the impediment to contracting around a dispreferred default. Because of the inevitable contractual inertia described above, choosing a default preferred by parties with high costs of failing to contract $\left(f_{i}\right)$ will, all other things equal, reduce the costs from failing to contract. Even if the propensity of different contracting types to contract around alternative defaults is the same, that does not mean that the costs of failing to contract will be equal.

For example, let us consider again the question of at-will versus justcause employment defaults. A just-cause default-because of contractual inertia-may create legal protection for wrongful discharge that, for a proportion of the workforce, is redundant with independent reputational deterrence of such terminations. But there is no reason to think that the costs of this inefficiency will be equal to the costs of the inefficiency that stems, under an at-will default, from subjecting another portion of the work force (working for employers with lower reputational constraints) to the harms of unreviewable wrongful discharge. Arguments can be made that either inefficiency might be greater. ${ }^{45}$ Our point here is only to observe that because the inefficiencies from failing to contract around the alternative defaults flow from such different causes, it is unlikely that these failure-to-contract costs will be approximately even.

For example, focusing now on the differences in costs of failing to contract around, let us assume that the costs of private contracting, public contracting and the propensity to contract around dispreferred defaults are the same for just-cause (jc) and at-will (aw) defaults. ${ }^{46}$ Specifically, imagine that $c_{\mathrm{aw}}=c_{\mathrm{jc}}=1, e_{\mathrm{aw}}=e_{\mathrm{jc}}=0$ and that prop $\mathrm{p}_{\mathrm{aw}}=$ prop $_{\mathrm{jc}}=.5$. Under these assumptions, if the costs of failing to contract are higher for just-cause types (who are subjected to underdeterrence) than for at-will types (who are subjected to overdeterrence), then just cause will again be efficient even if only a minority of contractors substantively prefer this protection. For example, if we assume that $f_{\mathrm{aw}}=5$ but $f_{\mathrm{jc}}=10$, then the just-cause default will be effi-

45. See generally J. Hoult Verkerke, An Empirical Perspective on Indefinite Term Employment Contracts: Resolving the Just Cause Debate, 1995 WIS. L. REV. 837, 869-96.

46. The assumption that the propensity of different contracting types to contract around dispreferred defaults is obviously at odds with our earlier argument that the at-will default will be relatively sticky -in the sense that a lower proportion of just-cause contractors would contract around it. But we make this alternative assumption to focus on differences in the $f_{i} s$. 
cient even if as many as sixty-four percent of the contractors prefer at-will treatment.

\section{Penalty Defaults THAT ForCe PRIVATELY INFORMED CONTRACTORS TO REVEAL THEIR "TYPE”}

The point of the foregoing analysis is to demonstrate that there is a rich set of efficiency rationales for minoritarian defaults that are independent of using penalty defaults to induce contractors to reveal information about their type. As emphasized in our original article, penalty defaults can be used to induce three types of information forcing: (1) inducing the parties to provide courts with better information about their intent (hence reducing the public cost of gap-filling as with the zero-quantity default); (2) inducing one contractor to correct another's mistaken beliefs about what the law is (as in the previous discussion of just-cause defaults); and (3) inducing one contractor to reveal private information about herself or some fact pertinent to the contract (as in the suggestion that the Hadley rule might induce high-damage millers to reveal their type).

Penalty defaults used to induce information about contractors' types are a special case of a minoritarian default based on different propensities to contract around. Private information about types can also give rise to different propensities to expressly contract because bad types may be more likely to contractually pool with good types in the shadow of some defaults. Our original Hadley model was a striking example of the different propensities to contract around. ${ }^{47}$ In our example, none of the good contract types opted out of the expanded liability default, but all of the bad types (i.e., the high-cost millers) were willing to contract around the limited liability default. ${ }^{48}$ In one sense, the limited liability default is actually a kind of majoritarian rule because a majority of the contractors (the low-cost millers) would prefer it. The limited liability rule nonetheless served as a striking departure from setting defaults to minimize the costs of express contracting. In our simple model, the limited damages default was more efficient than the expansive damages default - not just despite, but because it induced more contracting. The example showed that the benefits of information revelation could outweigh the costs of express contracting.

47. See Ayres \& Gertner, supra note 9.

48. If we let the subscripts $H$ and $E$ denote the Hadley and expanded liability defaults, then our original example assumed that $95 \%$ of contractors were good types (i.e., $\alpha_{H}=.95, \alpha_{E}=.05$ ) and showed that there could be strikingly dissimilar propensities to contract around the two defaults. In our initial example, $\beta_{H}=0$ and $\beta_{E}=.05$. Thus, $0 \%$ of good types contracted around their dispreferred expanded liability default, while $100 \%$ of bad types contracted around their dispreferred Hadley default. 
Adler's insightful analysis focuses solely on penalty defaults geared to the revelation of type information. His chief thesis concerns the ways that good types can cross-subsidize the prices paid by bad types in pooling equilibria. Adler correctly sees that bad types may often receive a subsidized price by pooling with - and hence, in the eyes of the other side, becoming indistinguishable from - the good types. Bad types confronted with a penalty default may be reluctant to contract around it in ways that distinguish themselves from the good types because doing so may cause the bad types to face higher, nonsubsidized prices. In an earlier article, we identified a similar reluctance to separate that was also based on the prospect that bad types would have to pay substantially higher prices in a separating equilibrium. ${ }^{49}$ When one side has private information and the other side has market power, separation may allow the side with market power to charge a supracompetitive price. Adler correctly shows that reluctance to separate might not be caused just by lack of market power, but also by a subsidization effect.

This descriptive subsidization insight leads Adler to two normative implications: (1) penalty defaults are only efficient in a narrow set of circumstances; and (2) lawmakers will have great difficulty identifying whether such circumstances exist. While we agree with the subsidization point, we do not believe it points as strongly toward these normative conclusions.

First, consider the narrowing point. Showing that bad types will have a reluctance to separate in a broader range of circumstances is different than showing that penalty defaults cannot be efficient. Adler carefully avoids making such a claim. When either the subsidization or the market-power effect creates reluctance, bad types will need to choose between the cost of sticking with the penalty default pool and the cost of higher prices if they separate. More extreme penalties may be sufficient to induce separation. Indeed, Adler's own model suggests that penalty defaults can still be most efficient for some parameter values. ${ }^{50}$

Moreover, Adler's own analysis of "case invariant liquidated damages" provides a valuable insight about what types of penalty defaults are most likely to induce separation - that is, most likely to increase the propensity of bad types to contract around. ${ }^{51}$ What Adler calls "case invariant liquidated damages" are an example of "untailored majoritarian defaults." Unlike a hypothetical rule which is tailored to give each contracting party the gapfilling provisions that they would have wanted in this particular contract, an untailored majoritarian default is selected to correspond to the desires of the majority of contractors. ${ }^{52}$ It has long been understood that untailored ma-

49. See Ayres \& Gertner, supra note 2.

50. See Adler, supra note 1, at 1570, 1582.

51. See id. at $1570-72,1582$.

52. See text accompanying notes 12-17 infra for problems with implementing majoritarian rules. See also Ayres, supra note 18 , at 14 . 
joritarian rules act as penalty defaults with regard to the minority contract types, but Adler shows that untailored defaults will not create the same crosssubsidization and attendant separation reluctance that more tailored majoritarian rules create. Thus, Adler has not only identified an important problem with implementing penalty defaults (his subsidization reluctance), he has identified a way that lawmakers can mitigate the problem.

Instead of seeing Adler's analysis as a limitation on when penalty defaults are appropriate, we see this part of his analysis as an important argument in favor of untailored, relative to tailored, majoritarian defaults. Adler seems to fight the constructive power of this insight. He correctly points out that untailored rules can create some ancillary inefficiencies of their own, but he overlooks that they can also reduce the cost of ex post judicial gapfilling for those who do not contract expressly. We may prefer untailored to tailored types of majoritarianism, not because we want to reduce the costs of ex post gapfilling but because untailored rules induce more bad types to reveal themselves and hence cause more efficient ex ante precaution taking. Lawmakers will often have a nondichotomous choice about how relatively tailored or untailored they want to make a majoritarian default. This again relates to our prior discussion of whether the defaults should be "rules" or "standards." Choosing penalty defaults that on the margin are more untailored or rule-like might promote information forcing while considering the contraindicating factors that Adler emphasizes.

Thus, we continue to be attracted to the idea of a zero-lost-profits damages default as a remedy for buyer breaches.53 A zero-damages default certainly constitutes an untailored, one-size-fits-all default. For example, sellers of a new automobile who have negotiated an unusually high price may be reluctant to contract around this penalty default-not because of a crosssubsidization reluctance, but because of a market-power reluctance. Consumers informed that they are about to sign a high-markup contract might think better of it and continue haggling at this dealership or others. The high-profit sellers might respond to a zero-lost profit default by merely contracting for a liquidated amount that was small enough not to distinguish the sale from other sales with more normal profits. But even here, the law could make progress by taking more seriously the implicit representations of fact that are made when parties contract around defaults.

In using penalty defaults to induce parties to reveal type information, the law intends that by contracting around, one side or the other will implicitly represent information about the profferor's type. Since parties implicitly covenant that their implicit representation will be true, an attempt to contract around a zero-damage default with a liquidated damages clause which sub-

53. See Ayers \& Gertner, supra note 12, at 99 n.57; see also Ian Ayres, Three Proposals To Harness Private Information in Contract, 21 HARV. J.L. \& PUB. POL'Y 135 (1997). 
stantially understates one's true damages may constitute an implicit misrepresentation of fact. The law might require liquidated damage defaults to be enforceable to accurately state the lost profit of the defendant - or might even hold sellers liable (for breaching their implicit warranty that all implicit representations are true) for negotiating clauses with underliquidated amounts that were not so denominated. Under such a system, sellers with private information that the contract price is exorbitant might still be reluctant to expressly contract for any liquidated damages - but failing to do so might also send a positive message to a potential buyer.

We are more attracted to the second normative implication-namely that it will often be difficult for lawmakers to know whether a penalty default will be efficient. Indeed, we argued this point ourselves with regard to separation reluctance caused by market power. We agree with Adler that penalty defaults can go badly wrong if they're ineffective in inducing separation. In efficiency terms, it may be better to have the parties pool around a tailored hypothetical damages default rather than to pool around a substantively inefficient penalty default. And we agree with Adler that courts and other lawmakers will often lack crucial information in order to determine beforehand whether a particular penalty will be effective in inducing separation. But Adler ignores that policymakers can often assess after the fact whether a particular penalty is effective in inducing separation. If diverse contractual types continue to pool in the shadow of a penalty default, lawmakers could experiment with a more severe untailored penalty or revert to a majoritarianbased default. For example, both the Hadley and Empire ${ }^{54}$ defaults seem to have succeeded in inducing at least partial separation. It is a usual practice of common carriers to offer a menu of differently-priced damages for delays. A shipper's choice of such an insurance contract allows for significant separation. 55 Ex ante assessment is often not possible, but ex post assessment may be sufficient to warrant experimentation with penalty defaults.

At the end of the day, lawmakers with imperfect information must stand ready to decide gapfilling questions. While Adler never takes a substantive position on how the courts should have decided Hadley and Empire, we bet that he is in favor of the defaults that give bad types a larger incentive to contract around. We also bet that Adler favors the law of mistake, which also has penalty-default, type-forcing quality. For example, section 153 of the Restatement (Second) of Contracts allows a contractor who is unilaterally mistaken about a basic assumption to void a contract if "the other party had reason to know of the mistake." 56 The default possibility of voidability is a

54. Empire Volkswagen v. World-Wide Volkswagen Corp., 814 F.2d 90 (2d Cir. 1987).

55. Of course, lawmakers might observe some separation under a penalty default but still may not be able to assess whether the separation is sufficiently complete. But Adler's central worry, that the parties will not separate at all in equilibrium, is often easily knowable after the fact.

56. RESTATEMENT (SECOND) OF CONTRACTS $§ 153$ (1979). 
penalty that the informed contractor can only avoid by revealing information. Indeed, in a Hadley-like fact pattern, a carrier could argue that a basic assumption of its promise to perform or pay damages was the belief that the miller would only have foreseeably low damages. Any evidence that the miller knew that it had high damages, but failed to correct the carrier's mistaken assumption, might be grounds for voiding the carrier's duty to pay damages at all..$^{57}$ A slightly expanded reading of the common law of mistake thus can be seen as a penalty default to induce knowledgeable contractors to correct the other side's mistakes of law or fact. Of course, Adlerian reluctance may induce bad types to remain silent here as well, but the more severe and untailored penalty of voidability-with possible forfeitures, instead of merely limited damages-may be sufficient to induce separating disclosure.

The modern law of unconscionability may also be seen as a penalty default to induce an informed party to disclose and explain information-not just about the terms of the contract but about facts pertinent to its performance. Building on the notion that it is procedurally unconscionable for a promissor to be unfairly surprised by the terms of the contracts, courts are beginning to impose a duty to disclose facts pertinent to the other side's performance. For example, Langemeier $v$. National Oats Co. ${ }^{58}$ concerned a plaintiff/agronomist who agreed to sell popcorn to defendant. The defendant (who also had provided the plaintiff with the popcorn seed) had failed to explain to the plaintiff (who had never grown popcorn before) that popcorn needed to dry twenty days in the field after maturing. When the popcom crop was badly damaged by freezing weather, the Eighth Circuit set aside the contract because of the defendant's nondisclosure. Our unconscionability can be interpreted as the type of penalty default which Adler criticizes because failure to disclose information about the probability of nonperformance or the consequences of nonperformance can lead to the penalty of nonenforcement. Type-forcing penalty defaults are not a radical departure from existing contract rules. Rather, aspects of existing mistakes and unconscionability law (as well as the venerable Hadley rule itself) are consistent with the notion that contract law can beneficially induce more separation by penalizing informed parties who fail to disclose pertinent information to the other side of the agreement.

57. See also id. $\S 161$ (c) ("A person's nondisclosure of a fact known to him is equivalent to an assertion that the fact does not exist ... where he knows that disclosure of the fact would correct a mistake of the other party ...."); id. \$ 201(2)(a) ("Where the parties have attached different meanings to a promise ... it is interpreted in accordance with the meaning attached by one of them if ... that party did not know of any different meaning attached by the other, and the other knew the meaning attached by the first party ....").

58. 775 F.2d 975 (8th Cir. 1985). 


\section{CONCLUSION}

The first generation of default theorists had a simple and elegant theory of default choice: Contractual gaps should be filled with the hypothetical term that most contractors would have wanted. This majoritarian standard has great appeal and, other things being equal, we wholeheartedly support it. The only problem is that other things are not always equal. In this essay, we have identified five other aphorisms that are equally valid. Ceteris paribus, efficiency-minded lawmakers should favor defaults that:

(1) impose lower costs of public gap filling;

(2) produce higher positive externalities;

(3) have higher costs of express contracting;

(4) are preferred by those with lower propensities of contracting around other rules; or

(5) are preferred by those with higher costs of failing to contract around other rules.

We sketched possible scenarios where these principles could trump the majoritarian impulse-causing defaults substantively preferred by only a minority of contractors to be efficient.

Adler's fine contribution is consistent with our major thrust that the "majoritarian" or "hypothetical" approach to default choice is insufficient to assure efficiency. Adler's demonstration of the reluctance effect further discredits any simple-minded notion that majoritarian defaults will merely induce minorities to contract efficiently for alternative provisions. Rather, in Adler's analysis, the choice about whether separation occurs is largely independent of a simple-minded analysis of transaction costs. Adler is also the first to see that untailored defaults may be more effective at inducing separation than tailored defaults because they do not give rise to the subsidization reluctance that may induce inefficient pooling when tailored defaults are used. His analysis suggests that an untailored default may be more effective at information forcing than tailored defaults. Again, these are considerations far removed from simple majoritarian impulse.

While we have tried to undermine majoritarianism by identifying competing impulses, it is also important to emphasize that the majoritarian approach can also be criticized as being conceptually incomplete. A majoritarian rule derives from determining what similarly-situated parties would have contracted for. But what defines "similarly-situated?" In the Hadley example, it might mean buyers and sellers generally, or it might mean shippers and carriers generally, or it might mean millers and carriers, or it might mean millers with high lost profits from delay, or it might mean very riskaverse millers and risk-neutral carriers. Models of default rules (ours in- 
cluded) largely ignore this question by assuming a well-defined set of contractual interactions for analysis. ${ }^{59}$

A second problem in defining the majoritarian rule is to identify the information structure for the hypothetical contract. Easterbrook and Fischel argue that a court ought to apply the "term that the parties would have selected with full information and costless contracting." 60 This rule is problematic when parties do not contract around the default. Private information may not be revealed in the contracting process, so that the other party's actions can not be affected by the information. ${ }^{61}$ The full information contract may be quite inefficient ex post if, as in the Hadley example, a carrier fails to take extra precautions since it did not know how costly delays would be to the miller. Finally, lawmakers have difficulty divining what the majority of contractors want. Because of inertia, a majority of contractors may fail to contract around a variety of defaults. And, because of heterogeneity, a majoritarian default may not even exist-there may only be a plurality default.

In an earlier draft, Adler concluded that a judge or legislator should be "skeptical of her ability to establish an efficient penalty-default rule" and instead should more often trust her instincts "to provide a traditional tailored default rule, the rule she believes the parties before her would have chosen had they contemplated the contingency presented."62 Here, Adler is going further than merely arguing that lawmakers should presumptively set (untailored) majoritarian rules. He seems to be suggesting that judges should presumptively set the default to be the more (tailored) hypothetical rules that individual contractors "before her would have chosen." We disagree. While Adler's final version no longer suggests any presumption in favor of tailored hypothetical defaults, we worry that readers will mistakenly conclude that any "criticism" of penalty default theory amounts to an endorsement of (untailored) majoritarian or (tailored) hypothetical defaults. Such a conclusion is unwarranted. While a lawmaker's task is difficult and skepticism about setting penalty defaults is often warranted, we simultaneously are skeptical that judges have sufficient information to identify tailored hypothetical pro-

\section{Charny refers to this as the dimension of generality:}

For example the adjudicator deciding whether employment is at will might conduct a detailed investigation into the understandings of the particular worker and employer involved in the dispute. Alternatively, she might simply announce a construction of the hypothetical bargain based on a generalization about ail firms and workers and applicable to all such transactions.

Charny, supra note 25 , at 1820.

60. Frank H. Easterbrook \& David R. Fischel, The Corporate Contract, 89 ColuM. L. REv. 1410,1433 (1989).

61. See Lewis A. Kornhauser, The Nexus of Contracts Approach to Corporations: A Comment on Easterbrook and Fischel, 89 CoLUM. L. REV. 1449, 1460 (1989).

62. Barry E. Adler, The Questionable Ascent of Hadley v. Baxendale 1, 43 (Oct. 30, 1998) (unpublished manuscript, on file with the Stanford Law Review). 
visions. Adler's analysis could reasonably lead readers toward agnosticism about default choice. Lawmakers will often not have sufficient information to choose the efficient default. But it is surprising that Adler (at least in a previous draft) preferred tailored, hypothetical defaults when his model suggests that untailored majoritarian rules will be less subject to the inefficient pooling which he has admirably identified. In short, skepticism about judges' abilities to tailor is at least as warranted as skepticism about judges' abilities to set efficient penalties.

The determination of the efficient default requires a careful analysis of the contracting environment starting with an understanding of the underlying causes of contractual incompleteness and a determination of the impact of different default rules on the contracting process. Adler's theoretical models, as well as our own and others, help us understand what the elements of that analysis should include. These reductive models can highlight unnoticed possibilities - such as the possibility that minoritarian defaults might be efficient. But these models are not useful for proving impossibilities. Adler's subsidization reluctance may narrow the range of circumstances where penalty defaults are efficient, but to show that penalty defaults and other minoritarian defaults are unlikely to be inefficient requires richer information about the world. 
HeinOnline -- 51 Stan. L. Rev. 1614 1998-1999 